\title{
Islam Hadhari's Principles and Reward Management Practices: A Conceptual Study in Malaysian Private Organizations
}

\author{
Wan Shakizah Wan Mohd Noor \\ University Utara Malaysia \\ E.mail: shakizah@uum.edu.my
}

Zulkiflee Daud

University Utara Malaysia

E.mail: zulkiflee@uum.edu.my

\author{
Mohd Faizal Mohd Isa \\ University Utara Malaysia
}

E.mail: m.faizal@uum.edu.my

\begin{abstract}
Received: October 02, 2011 Accepted: October 27, $2011 \quad$ Published: November 1, 2011 doi:10.5296/ijhrs.v1i1.1043 URL: http://dx.doi.org/10.5296/ijhrs.v1i1.1043
\end{abstract}

\begin{abstract}
Many best practice models exist that describe successful approaches to reward management which influence by the cultural, legal, organizational and administrative challenges in Islamic world. Thus, the decision in setting and designing reward programs in raising productivity through human effort has always been controversial. Studies that were undertaken in numerous countries have shown varying degrees of success of such practices. Even though there is a substantial amount of foreign literature on this subject, there is a paucity of information concerning the extent of such application in Malaysia. As Malaysia is a predominantly Muslim country, Islam, through national culture influences organizations. This paper is an attempt to provide further insights into the theory and practice of reward management in the local context as Malaysia is implementing Islam Hadhari's principles in the country. The study adopts a qualitative approach. A tentative research model is developed first, based on an extensive literature review. The qualitative field study then is carried out to explore the perceptions of
\end{abstract}


reward management in the Malaysian private organizations from the Islamic perspective. Twelve Malaysian private organizations of various sizes are studied via interviews with key personnel. The paper will also contribute theoretically and practically by providing direction and suggestions in designing and implementing the reward programs for the private organizations in the Malaysian environment.

\section{KEYWORDS: $\quad$ Reward management, Islam Hadhari, Culture}

\section{Introduction}

Islam Hadhari was a key campaign issue during the Malaysia general elections in 2004 (Chong, 2006) as the former Prime Minister Dato' Seri Abdullah Ahmad Badawi who won the election and presented his vision towards a 'progressive Islam'. The execution of Islam Hadhari took place as a model for the rest of Islamic world. Pandian (2008) adds, Islam Hadhari gives importance to excellence in living, enabling Malaysia to be a model Islamic state with its community which is progress-oriented, highly skilled, noble, and well-disciplined. He states also that the approach of Islam Hadhari seeks to balance man's responsibility in the here and the hereafter, that is this life and the next. Adding to this, the multi-cultural groups in Malaysia share the Islamic ethical value and this study needs to examine and discuss human resource management, specifically on reward management practices which are more culture-specific to Malaysia. Therefore, the reward management practices in countries where Islam plays a dominant role in governing the peoples' lives needs to reflect Islamic values held by their people.

Reward refers as the total amount of monetary and non-monetary rewards and benefits provided to an employee by an employer in return for work performed as required and as part of an employment relationship (Armstrong and Murlis, 2007; Milkovich,

Newman \& Gerhart, 2010). However, Herzberg et al. (1959) believed that compensation (which is Americanized term for rewards) is what he described as a hygiene factor. Rewards are what employees receive for performance. However, in order to achieve improvements in performance, different reward programs must be applied by the respective organizations in line with their organizational cultures and values.

A number of studies have been conducted by researchers and Islamic scholars on specific matters in Muslim countries, such as economics or banking and finance issues, but none is related to the non-monetary and monetary rewards, cultural orientation and internal/external environment factors from an Islamic perspective (Khan, 1991; Tayeb, 1997; Loqman, 1991; Heim, 2004; Ramadan, 2005). Furthermore, the studies conducted on the impact of Islam on human resource management (HRM) matters are very few (Tayeb, 1997). Therefore, the study aims to fill the gap, by investigating four principles of Islam Hadhari in relation to reward systems in the Malaysian context. Hence, this study examines whether Islam Hadhari's principles are embedded the reward management practices or not in Malaysian private organizations. 


\subsection{Literature Review}

\subsubsection{Islam Hadhari’s Principles}

In some western cultures, religion and faith do not play a prescriptive role in societal and organizational life. However, Malaysia is 60.4 percent Islamic faith. Additionally the faith permeates all facets of social and organizational interaction. Islam sees the human race as singular and coming from the same singular God (Noor, 2004). Noor (2004) also states that the concept of race has no place in either the theology or praxis of Islam. The Malaysian Prime Minister, Abdullah Ahmad Badawi spelt out his vision of Islam Hadhari or Civilization and comprehensive Islam. Badawi is trying to promote his vision of a modern, progressive, tolerant and multicultural Islam where Muslims are encouraged to learn from interaction with other communities. Islam Hadhari is neither a new religion nor a new mazhab (denomination), but an effort to bring the Ummah (Islamic community) back to the fundamentals of the Quran and the Hadith (the Traditions of the Prophet Muhammad) which formed the foundation of Islam civilization (Hassan, 2004). It could well be a paradigm of how Malaysian Muslims should see Islam in the context of a multi-racial Malaysia facing a changing world and also considering the sensitivity of non-Muslims community towards the increasing 'Islamization' of Malaysia.

Bashir (2005) adds that these principles have been formulated to ensure that the implementation and approach do not cause anxiety among any group in Malaysia. Moreover, the government has to make sure its religious departments and officers are well-versed in the principles of Islam Hadhari.

Tayeb (1997) mentions that Islam is an all-encompassing creed, governing every aspect of life, public and private, political and economic, and as such is relevant to business activities. The Quran advocates a system based on individual enterprise and individual reward. Tayeb (1997) argues that the cross-national research is required to investigate the implications of Islam on organizations which operate in Muslim countries with regard to human resource management practices. Therefore, given the pervasiveness of Islam and its influence on various spheres of material as well as spiritual life in most Muslim countries, it is possible to discern certain patterns in Muslim workplaces which are compatible with their Islamic origins. In this sense, as well as utilizing western Human Resource Management (HRM) concepts and studies, the Malaysian findings may inform and sensitize leaders and managers who have Muslim staff.

The study focuses on four Islam Hadhari's principles:

\section{Mastery of knowledge}

According to Prophet, 'seeking knowledge is an obligation for every Muslim man and woman' and Islam also repeatedly instructs man to use his powers of intelligence and observation (Surah Al-Alaq: 1-5 ).

\section{Balanced and comprehensive economic development}

An approach which combines the efforts to establish ethical economic practices and the ability to conduct economic activities effectively in tandem with local and 
international economic developments (Sūra 62: Jumu'a, Section 2 [10]).

\section{A good quality of life}

It can be achieved if the country especially Malaysia succeeds in fulfilling the basic needs of life such as preserving religion, improving the status of education of its people, providing a peaceful life, ensuring the right to own property and make providence to the generation of the future (Department of Islamic Development Malaysia Putrajaya, 2005: p.33).

\section{Cultural and moral integrity}

It is important that cultural and religious diversity must be protected based on a value and moral system which is strong, lofty and honourable in order to enhance the development of Malaysia (Department of Islamic Development Malaysia Putrajaya, 2005: p.39).

\subsubsection{Non-Monetary and Monetary Rewards}

Chiang and Birtch (2005) found that reward preference is tied to a reward ability to satisfy employee's needs and fit with cultural-bound values. Financial rewards are important to most individuals and have shown a strong desire for individual achievement and for self-interest in country such as United States and most other Western countries (Hofstede 2001, 1991, 1980a, 1980b). Furthermore, Ger and Belk (1996) claim that the consumption-based orientation to 'happiness-seeking' that is commonly labelled materialism has generally been seen as a Western trait. Materialism now seems to have diffused to ever more of the world's people (Ger and Belk, 1996). With the overall aim of material gain on the other hand, country such as Malaysia which is characterized as having strong social needs, quality of life and moral integrity focus on non-financial rewards. In such cultural environments, non-monetary rewards of recognition and praise (Chiang and Birtch, 2005; Mendonca and Kanungo, 1994; Vance, McClaine, Boje, and Stage, 1992) are appreciated.

As study by Islam and Ismail (2008) discovered that money is perceived a good motivator by US and Malaysia, and it is expected that promotion will receive higher priority. Indeed, promotion has been continuously pushed to higher priority over the years in US. The same case happened to Malaysia in 2004 where the job security has maintained stability in its ranking. Islam and Ismail (2008) enlighten that contrary to Malaysia, US is more concerned with job security over promotion matters. However, 'interesting work' has maintained middle ranking among factors in all surveys conducted in Malaysia and US. Malaysian employees are not much concerned about the appreciation of their work compared to the other factors. Conversely, the 'full appreciation of work done' has been favored by the US employees (Islam and Ismail, 2008). It is observed that monetary reward plays a major role in motivating Malaysian employees compared to US employees are more preferred to appreciation and recognition. This concludes that money has been a predominantly preferred motivator amongst Malaysia employees (Islam and Ismail, 2008).

\subsubsection{Reward Program Influences}

As discussed by Gilley and Maycunich (2000), an effective development of compensation and rewards philosophy reflects the importance of change and remaining 
flexible in adapting to the demands and constraints of a dynamic, ever-shifting business environment. They found that pay and rewards in most organizations have not evolved to effectively compensate individuals for their increased effort, employee contribution and learning and development. Important to this study would also be the effect on employee productivity. Huang, Lu, Tang \& Huang, (2004) also indicated that human resource executives have been focusing on effective ways to increase employees' commitment and satisfaction and which will be able to reduce the cost related to recruitment and turnover. Furthermore, practising fairness in reward as one to which employees is most sensitive is important in order to improve individual commitment and job performance (Huang et al., 2004). Therefore, a well-designed development of compensation and reward program exhibits attribute rewards which are linked to business strategy in-order that employees know what is being rewarded and why rewards support the organization's culture (Gilley \& Maycunich, 2000). (Only one attribute here will be needed to be extended and put to the 'Hadhari' test). However, the truth about employee reward perception is more complex than the assumption that employees view each reward element in isolation from all others (Davenport \& Roberts, 2005). The authors also mentioned that social scientists who studied employee attitudes have observed that employees view their reward portfolios holistically; forming generalized impressions about how much the organization values their contributions and cares about their well-being. In the Malaysian setting, this holism will, to the majority of employees following Hadhari's principles, include moral issues and obligations.

Appelbaum and Kamal (2000) also found that there was a clear positive relation between employee loyalty/retention and compensation. Dutton (1998) noted that lack of employee recognition is cited as a major and recurring source of employee turnover (cited in Appelbaum and Kamal, 2000) and this has resulted in firms losing disenchanted innovators as well as experiencing lower levels of effort and even sabotage and espionage. However, Appelbaum and Kamal (2000) explained that employee motivation through non-monetary rewards may be accomplished by decision makers paying closer attention to the needs of their employees, in particular to relevant factors discussed before, and this may ultimately result in improved revenues through greater productivity, increased employee satisfaction or higher output, reduced employee absenteeism, lower employee turnover rates and a greater overall synergy in increasing the firm's efficiency and bottom line.

\subsection{Research Method (Qualitative Field Study)}

\subsubsection{Sample Selection}

Convenience sampling was used in the initial qualitative field study. This approach has the ability to obtain extensive information quickly and effectively (Zikmund, 2003). Twelve selected private organizations were chosen from the convenience sample of Malaysian private organizations registered on The Federation of Malaysian Manufacturers (FMM) (FMM, 2003). Furthermore, FMM consists of manufacturers and companies registered in Malaysia as large, small or medium-sized industries, foreign or locally-owned or operated on a joint-venture basis. FMM members also represent $23 \%$ of the 861 companies listed in KLSE. Of the 2,135 FMM members companies, $47 \%$ of the companies have already 
obtained their ISO certification (FMM, 2003).

A semi-structured interview technique was used. The interview plan followed the guidelines of Whiteley et al. (Whiteley et al., 1998 and Patton, 1990). The interview questions were developed and tested by a small group of executives from 'selected' private organizations in Malaysia. All participants were asked the same interview questions, relating to the variables to be validated (Morse, 2005) which were Islam Hadhari's principles, non-monetary and monetary rewards and also reward program influences (employee contribution, productivity, loyalty and employee turnover. Morse (2005) also noted that in this style of interviewing, all participant interviews might be considered equivalent, and the information gathered was compared and analyzed item by item.

\subsubsection{Data Analysis}

Two sequential stages were undertaken in analyzing the qualitative data. As this study in this phase was more on exploratory than confirmatory in nature, "content analysis" was chosen in analyzing the interview transcripts. Content analyses were carried out in two stages. First stage dealt with single interview transcripts, while second stage dealt with cross interview transcripts. It was noted that all content analyses were done manually and a combination of inductive and deductive approaches was used to categorize the factors and variables. The first stage was to review the participant's transcript by reading the transcript line by line, and at the same time scanning to identify the key words from interview transcript. Subsequently, the data were categorized into different codes. These codes reflected the factors and variables for the initial research model. These developed codes and categories were cross-referenced with the literature review. Finally, the factors and variables from initial steps were organized in table or matrix form.

\subsection{Findings}

The size of Malaysian private organizations interviewed is varied from 300 to 7,000 employees. Nine of private organizations were foreign organizations and other three were local companies. All key personnel interviewed were involved in the area of compensation and benefits in developing and implementing the reward programs.

Table 1.1 presented the reflection of the relationship between the factors of Reward Program Influences. It could be seen, during the interview process, the reflection of the relationship between the factors were derived from the field interview process. This information was extracted from the interview transcripts using content analysis. Each row of the table presents the pair of factors and corresponding direction of the reflection of the relationship for both factors, while column of the table identifies the related respondents. The $\sqrt{ }$ represents Islam Hadhari's principles embedded the reward management practices. 


\section{Macrothink $\Delta$ Institute $^{\text {tm }}$}

Table 1: Islam Hadhari's principles embedded the reward management practices.

\begin{tabular}{|l|l|l|l|l|l|l|l|l|l|l|l|l|l|}
$\begin{array}{c}\text { Link Between } \\
\text { Factors }\end{array}$ & C1 & C2 & C3 & C4 & C5 & C6 & C7 & C8 & C9 & C1 & C1 & C1 \\
MKW \& MR & $\sqrt{ }$ & $\sqrt{ }$ & $\sqrt{ }$ & $\sqrt{ }$ & $\sqrt{ }$ & $\sqrt{ }$ & $\sqrt{ }$ & $\sqrt{ }$ & $\sqrt{ }$ & $\sqrt{ }$ & $\sqrt{ }$ & $\sqrt{ }$ \\
\hline BCED \& MR & $\sqrt{ }$ & $\sqrt{ }$ & $\sqrt{ }$ & $\sqrt{ }$ & $\sqrt{ }$ & $\sqrt{ }$ & $\sqrt{ }$ & $\sqrt{ }$ & $\sqrt{ }$ & $\sqrt{ }$ & $\sqrt{ }$ & $\sqrt{ }$ \\
\hline GQL \& MR & $\sqrt{ }$ & $\sqrt{ }$ & $\sqrt{ }$ & $\sqrt{ }$ & $\sqrt{ }$ & $\sqrt{ }$ & $\sqrt{ }$ & $\sqrt{ }$ & $\sqrt{ }$ & $\sqrt{ }$ & $\sqrt{ }$ & $\sqrt{ }$ \\
\hline CMI \& MR & $\sqrt{ }$ & $\sqrt{ }$ & $\sqrt{ }$ & $\sqrt{ }$ & $\sqrt{ }$ & $\sqrt{ }$ & $\sqrt{ }$ & $\sqrt{ }$ & $\sqrt{ }$ & $\sqrt{ }$ & $\sqrt{ }$ & $\sqrt{ }$ \\
\hline MKW \& NMR & $\sqrt{ }$ & $\sqrt{ }$ & $\sqrt{ }$ & $\sqrt{ }$ & $\sqrt{ }$ & $\sqrt{ }$ & $\sqrt{ }$ & $\sqrt{ }$ & $\sqrt{ }$ & $\sqrt{ }$ & $\sqrt{ }$ & $\sqrt{ }$ \\
\hline BCED \& NMR & $\sqrt{ }$ & $\sqrt{ }$ & $\sqrt{ }$ & $\sqrt{ }$ & $\sqrt{ }$ & $\sqrt{ }$ & $\sqrt{ }$ & $\sqrt{ }$ & $\sqrt{ }$ & $\sqrt{ }$ & $\sqrt{ }$ & $\sqrt{ }$ \\
\hline GQL \& NMR & $\sqrt{ }$ & $\sqrt{ }$ & $\sqrt{ }$ & $\sqrt{ }$ & $\sqrt{ }$ & $\sqrt{ }$ & $\sqrt{ }$ & $\sqrt{ }$ & $\sqrt{ }$ & $\sqrt{ }$ & $\sqrt{ }$ & $\sqrt{ }$ \\
\hline CMI \& NMR & $\sqrt{ }$ & $\sqrt{ }$ & $\sqrt{ }$ & $\sqrt{ }$ & $\sqrt{ }$ & $\sqrt{ }$ & $\sqrt{ }$ & $\sqrt{ }$ & $\sqrt{ }$ & $\sqrt{ }$ & $\sqrt{ }$ & $\sqrt{ }$ \\
\hline MR \& EP & $\sqrt{ }$ & $\sqrt{ }$ & $\sqrt{ }$ & $\sqrt{ }$ & $\sqrt{ }$ & $\sqrt{ }$ & $\sqrt{ }$ & $\sqrt{ }$ & $\sqrt{ }$ & $\sqrt{ }$ & $\sqrt{ }$ & $\sqrt{ }$ \\
\hline MR \& EC & $\sqrt{ }$ & $\sqrt{ }$ & $\sqrt{ }$ & $\sqrt{ }$ & $\sqrt{ }$ & $\sqrt{ }$ & $\sqrt{ }$ & $\sqrt{ }$ & $\sqrt{ }$ & $\sqrt{ }$ & $\sqrt{ }$ & $\sqrt{ }$ \\
\hline MR \& EL & & & $\sqrt{ }$ & $\sqrt{ }$ & & & & $\sqrt{ }$ & & $\sqrt{ }$ & $\sqrt{ }$ & $\sqrt{ }$ \\
\hline MR \& ET & $\sqrt{ }$ & $\sqrt{ }$ & $\sqrt{ }$ & $\sqrt{ }$ & $\sqrt{ }$ & $\sqrt{ }$ & $\sqrt{ }$ & $\sqrt{ }$ & $\sqrt{ }$ & $\sqrt{ }$ & $\sqrt{ }$ & $\sqrt{ }$ \\
\hline NMR \& EP & $\sqrt{ }$ & $\sqrt{ }$ & $\sqrt{ }$ & $\sqrt{ }$ & $\sqrt{ }$ & $\sqrt{ }$ & $\sqrt{ }$ & $\sqrt{ }$ & $\sqrt{ }$ & $\sqrt{ }$ & $\sqrt{ }$ & $\sqrt{ }$ \\
\hline NMR \& EC & $\sqrt{ }$ & $\sqrt{ }$ & $\sqrt{ }$ & $\sqrt{ }$ & $\sqrt{ }$ & $\sqrt{ }$ & $\sqrt{ }$ & $\sqrt{ }$ & $\sqrt{ }$ & $\sqrt{ }$ & $\sqrt{ }$ & $\sqrt{ }$ \\
\hline NMR \& EL & & & $\sqrt{ }$ & $\sqrt{ }$ & & & & $\sqrt{ }$ & & $\sqrt{ }$ & $\sqrt{ }$ & $\sqrt{ }$ \\
\hline NMR \& ET & $\sqrt{ }$ & $\sqrt{ }$ & $\sqrt{ }$ & $\sqrt{ }$ & $\sqrt{ }$ & $\sqrt{ }$ & $\sqrt{ }$ & $\sqrt{ }$ & $\sqrt{ }$ & $\sqrt{ }$ & $\sqrt{ }$ & $\sqrt{ }$ \\
\hline
\end{tabular}

\section{Note:}

\section{ISLAM HADHARI'S PRINCIPLES}

- $\quad$ MKW - Mastery of Knowledge

- $\quad$ BCED - Balanced and Comprehensive Economic Development

- $\quad$ GQL - Good Quality of Life

- $\quad$ CMI - Cultural and Moral Integrity

NON-MONETARY AND MONETARY REWARDS

- $\quad$ MR - Monetary Rewards

- $\quad$ NMR - Non-Monetary Rewards

REWARD PROGRAMS INFLUENCES

- $\quad$ EP - Employee Productivity

- $\quad$ EC - Employee Contribution

- $\quad$ EL - Employee Loyalty

- $\quad$ ET - Employee Turnover

As indicated in Table 1, how this is derived can be explained as follows. For example, "MKW \& NMR" in row 5 of Table 1 represented that "Mastery of Knowledge" (MKW) was embedded the "Non-Monetary Rewards" (NMR), and this finding has been identified in all companies. This shows that all respondents ( $\mathrm{C} 1$ to $\mathrm{C} 12)$ supported the notion that mastery of knowledge embedded the non-monetary reward among exempt employees in the private organizations. Training and development are important to increase knowledge of employees 
to all levels.

Thus refer to another example for the reflection of the relationship between the factors is "MR \& EC". Colum "MR \& EC" shows that Monetary Reward (MR) impacts on Employee Contribution (EC). Specifically, column MR \& EC for respondent from organization C9 indicated that monetary rewards play an important role in motivating employees to be outstanding in their job. This shows there is strong relationship between monetary rewards and employees' contribution as it was observed that monetary reward plays a major role in motivating Malaysian employees. This concludes that money has been predominantly preferred motivator amongst Malaysia employees (Islam and Ismail, 2008). However, there was much evidence in the data that non-monetary rewards played an important role.

The conceptual framework of Islam Hadhari's principles and reward management practices from the interviews was developed via carefully looking at every single interview transcript. This is to identify the consensus among respondents in terms of new variables or the interaction of the initial variables in Islam Hadhari's principles, non-monetary and monetary rewards, and also reward program influences of the research model.

The focus of this study was to explore the categories and sub-categories that could influence the non-monetary rewards contributing towards reward program influences in the context of Malaysia private organizations. Based on the analysis of field study, a model that combined the answers from all respondents was developed (see Figure 1 in section 1.4). Figure 1 is also a schematic representation of the combination or joining together the categories and sub-categories which have the same elements, or have the same meaning. Simultaneously, the categories and sub-categories that are unique and cannot be combined with other sub-categories must be maintained. In addition, categories and sub-categories based on literature review were also being considered in developing the model.

Generally the field study validated the framework of the tentative research model. The respondents provided practical support to fine-tune the categories and sub categories. In addition, linkages between categories (factors) which were found from the field study make the research conceptual model appropriate to explain the impact of Islam Hadhari's principles towards non-monetary and monetary rewards in the context of Malaysia private organizations.

\subsubsection{Islam Hadhari's Principles}

Islam is a way of life and is present in every field of human existence which provides guidance for all aspects of life including individual and social, material and moral, economic and political, legal and cultural as well as national and international.(Hashim, 2007). Even though Islam Hadhari's has ten principles, specifically this study attempts to examine only four principles, namely Mastery of Knowledge, A Balanced and Comprehensive Economic Development, A Good Quality of Life and Cultural and Moral Integrity. Therefore, this study is expected to enhance understanding of the role of the Islamic Hadhari's principles towards the reward systems in the non-Western context of Malaysia. 
1.3.1.1 Mastery of Knowledge

2011, Vol. 1, No. 2

Hashim (2007) professes that training and development are important to increase knowledge of employees to all levels ensuring that this knowledge includes the general knowledge that can improve their faith (Surah Fatir 35: 28) and their religious practices. It was found that all twelve organizations recognized that Mastery of Knowledge relates to non-monetary and monetary rewards. This is consistent with the studies mentioned above. Kugel and Schostek (2004) empirically concluded that monetary rewards seem to have immediate effect on motivation to share knowledge. These aspects of organizational rewards can range from traditional economic rewards, such as salary and fringe benefits, to an almost unlimited variety of psychosocial rewards, such as praise from a supervisor and having a respected place in the informal work group (Reif, Newstrom, and Louis, 1976).

\subsubsection{A Balanced and Comprehensive Economic Development}

A balanced and comprehensive economic development requires an approach which combines the efforts to establish ethical economic practices and the ability to conduct economic activities effectively in tandem with local and international economic developments (Surah Jumu'ah 62: 10) (Department of Islamic Development Malaysia Putrajaya, 2005: p.30). All the organizations indicated that balanced and comprehensive economic development plays an important role in contributing to the attractive and valuable reward package. Even though this principle is one of the Islam Hadhari's principles, the respondents from organizations profess that they never use the term as referring to religion. Basically, the organizations have been implementing the principles indirectly as monetary rewards significantly related to economic conditions and stability.

This is consistent with many studies conducted previously such as Said, (2008); Shariff, (2003); Badawi, (2005); Bashir, (2005); Sauer, (1999); Khan, (1991); Hamidullah, (1979). The organization needs to reward people using the rules for righteous behaviour which leads the society to the wealth and economic stability (Baligh, 1998). The wealth must remain in constant circulation among all sections of the community and should not be a monopoly of the rich (Surah Al-Hasyr 59: 8) (Khan et al., 2010). The field study results provided the support for the proposition that a balance and comprehensive development will positively influence the non-monetary and monetary rewards.

\subsubsection{A Good Quality of Life}

Islam from the very beginning has stressed on the importance of a good quality of life (Department of Islamic Development Malaysia, Putrajaya, 2005: p.32). Essentially, a good quality of life can be achieved if the country especially Malaysia succeeds in fulfilling the basic needs of life such as preserving religion, improving the status of education of its people, providing a peaceful life, ensuring the right to own property and make providence to the generation of the future (Department of Islamic Development Malaysia Putrajaya, 2005: p.33). All of the respondents from twelve organizations stated that they also emphasized a good quality of life in their organizations. This is part of the recognition that should be given 
by organizations in appreciating the employees' contribution during their tenure of service with them. This is consistent with the results of the Malaysian prominent personalities/researchers such as Hashim, (2007); Badawi, (2005); Zin, (2005), Alhabshi, (2004), Hassan, (2004), and Bashir, (2005) that Islam Hadhari will focus on improving and enhancing the quality of life for every citizen, regardless of his or her religion. Therefore, the variable a good quality of life in combined model from field study is claimed to influence the non-monetary and monetary rewards.

\subsubsection{Cultural and Moral Integrity}

It is important that cultural and religious diversity must be protected based on a value and moral system which is strong, lofty and honourable in order to enhance the development of Malaysia. (Department of Islamic Development Malaysia Putrajaya, 2005: p.39). It was observed that all organizations shown positive feedback on cultural and moral integrity as they perceived this factor important in relation to the non-monetary and monetary rewards. Ashkanasy and Trevino, (2006) articulate that a reward system is very important to the organization because of the powerful influence of rewards and punishments on individual behaviour generally and on ethical/unethical behaviour. This is in agreement with past studies such as Levine, (1998); Koys, (2001); Martinez, (2005); Lublin, (2006); Halstead, (2007); Michealson, (2008) and Malaysian prominent personalities/researchers such as Zin, (2005), Badawi, (2005); Hassan, (2004), and Bashir, (2005). The field study provided the support for the proposition that cultural and moral integrity could affect the non-monetary and monetary rewards.

\subsubsection{Non-Monetary Rewards and Reward Program Influences}

Non-monetary rewards are based on the motivators by Herzberg's Two Factor of Motivation Theory (1959) which includes responsibility, recognition, advancement, achievement and growth. Reward program influences such as employee contribution, productivity, loyalty and employee turnover also play important role. They can be influenced by non-monetary and monetary rewards. It was found from the field study that all respondents from twelve organizations indicated all the factors as mentioned before to be significantly related to the contribution, productivity and employees turnover in reward program influences. This is consistent with previous investigations showed that in order for employees to be truly satisfied and motivated in their jobs, they must feel that they are contributing, learning and enjoying themselves at work (Herzberg et al., 1959; Markovich, 1997 coded by Appelbaum and Kamal, 2000; Allen, Shore and Griffeth, 2003; Takeuchi, 1981; Fein, 1983; Kanungo and Mendonca, 1988; Grensing, 1996; Comeau-Kirchner, 1999; Osborne, 2001; Armstrong and Murlis, 2004; Sachau, 2007; Seay, 2008).

The findings from field study showed respondents from C3, C4, C8, C10, C11 and C12 made remark that non-monetary rewards package somehow influence the employees' loyalty toward organization. However the respondents from organization C1, C2, C5, C6, C7 and C9 affirmed that loyalty among employees nowadays cannot be counted anymore. 


\section{Macrothink Institute"}

This is contrary with Oliver (1990) who stated that work rewards are significant in relation to loyalty and employee intent to leave within five years and satisfaction. On the other hand, Reichheld (2001) says that it isn't simply a matter of having better databases, measurement systems, or rewards programs. Outstanding loyalty is the direct result of the words and deeds-the decisions and practices-of commitment from the top to the bottom, from top executives to employees who have personal integrity. Reichheld (2001) also emphasizes that most of the top loyalty companies are equally forthright about telling employees where they stand. In addition, managers at many of these companies submit annually to 360-degree feedback-performance reviews from bosses, peers, and subordinates.

\subsubsection{Monetary Rewards and Reward Program Influences}

Monetary rewards reflect the hygiene factors by Herzberg's Two Factor of Motivation Theory (1959) which include basic pay, allowances, performance bonus/ incentives and benefits. It was observed that all respondents from twelve organizations mentioned the important of these monetary rewards affecting the rewards program influences such as employee contribution, productivity and employee turnover. This in line with past studies done by Herzberg et al., 1959; Markovich, 1997 coded by Appelbaum and Kamal, 2000; Armstrong and Murlis, 2007 among many others. Hence, organizations often reward employees who grab short-term profits and short change those who build long-term value and customer loyalty (Reichheld, 2001)

The same results from field study also showed the impact of monetary rewards package on employee loyalty. The respondents from organization C1, C2, C5, C6, C7 and C9 asserted that nowadays, it is hard to have employee loyal to one company. Unlike the old days, employee loyalty was pervasive. However, respondents from C3, C4, C8, C10, C11 and C12 indicated that monetary rewards significantly related to employees' loyalty in the organization. According to McShulskis (1997), the study found that 80 percent of employees surveyed would recommend their companies as the best place to work, but 40 percent would leave their current employers for only slightly higher pay. Schrag (2001) also asserts that one cannot buy employee loyalty and employees will go with a better offer if only the salary holds employees. 


\subsection{The Conceptual Research Model and variables}

Figure 1 is a conceptual research model that is derived from the interviews and literature review.

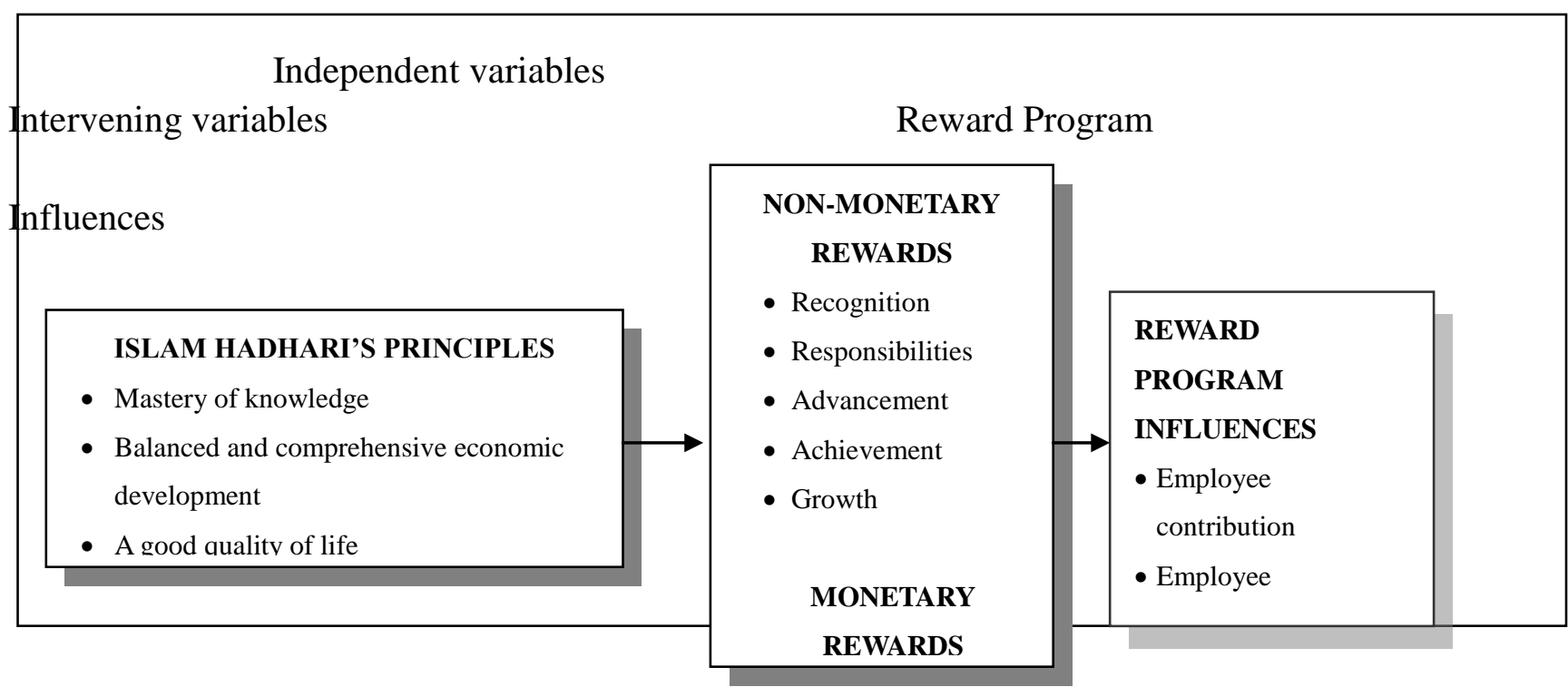

Figure 1: An Initial Conceptual Research Model

\subsection{Conclusion and Future Research Direction}

The results of the study are concluded as follows:

1. Four variables identified to be significant in influencing the rewards practices were mastery of knowledge, a balance and comprehensive economic development, a good quality of life and also cultural and moral integrity were mentioned by all companies.

2. Future plan is to study the conceptual research model further using a structural equation modeling approach (SEM). The model itself and a number of hypotheses will be tested in Malaysian private organizations.

3. Possible extension of this research can be explored in the future. As mentioned before, this study has limitations related to generalization of the findings. Future studies might want to include a larger sample size to make the findings more accurately generalised of the world's vast population. Data can be obtained from many more organizations, and more employees of various levels, positions and religious beliefs can be included as future respondents in future studies.

\subsection{Significance of Study}

Past studies have been conducted on specific matters such as work ethics, economics or banking and finance issues but little research reward management practices from an Islamic perspective specifically in Malaysian environment. The researchers examined the certain variables in different environment. (Khan, 1991; Tayeb, 1997; Loqman, 1991; Heim, 2004; Ramadan, 2005). Adding this dimension will enhance knowledge and give a better understanding of Islam Hadhari's principles and reward management practices that will, in turn, affect the employees' perceptions on the reward packages they receive. 


\section{References}

Alhabshi, SO 2004, 'Islam in Malaysia: Comprehensive development index', in Malaysia Achievement As An Islam Country. IKIM, Kuala Lumpur, 27th \& 28th February 2004.

Allen, DG, Shore, LM \& Griffeth, RW 2003, 'The Role of Perceived Organizational Support and Supportive Human Resource Practices in the Turnover Process', Journal of Management, vol. 29, no. 1, pp. 99-118.

Armstrong, M \& Murlis, H 2007, Reward Management: a handbook of remuneration strategy and practice, 5th edn, Kogan Page, London.

Appelbaum, SH \& Kamal, R 2000, 'An analysis of utilization and effectiveness of non-financial incentives in small business', The Journal of Management Development, vol. 19 , no. $9 / 10$, pp. 733-763.

Ashkanasy, NM, Windsor, CA \& Treviño, LK 2006, 'Bad apples in bad barrels revisited: Cognitive moral development, just world beliefs, rewards, and ethical decision-making', Business Ethics Quarterly, vol. 16, no. 4, pp. 449-473.

Badawi, AA 2005, 'Islam Hadhari: An Explanation', in Message. Department of Islamic Development Malaysia Putrajaya, Putrajaya.

Baligh, HH 1998, 'The fit between the organization structure and its cultural setting: aspects of Islamic cultures', International Business Review, vol. 7, no. 1, pp. 39-49.

Bashir, MS 2005, 'Islam Hadhari: concept and Prospect', Islamic University of Malaysia (KUIM), Kuala Lumpur, pp. 1-5.

Chiang, FFT \& Birtch, TA 2005, 'A taxonomy of reward preference: examining country differences', Journal of International Management, vol. 11, pp. 357- 375

Chong, T 2006, 'The ermerging politics of Islam Hadhari', Institute of Southeast Asian Studies, Singapore, pp. 26-46.

Comeau-Kirchner, C 1999, 'Improving productivity doesn't cost a dime', Management Review, vol. 88, no. 1 , p. 7.

Davenport, TO \& Roberts, DR 2005, 'Managers - The missing link in the reward change process', Journal of Organizational Excellence, vol. 24, no. 2, pp. 3-16.

Department of Islamic Development Malaysia Putrajaya 2005, Islam Hadhari : an explanation, 1st edn, Department of Islamic Development Malaysia, Putrajaya, Putrajaya.

Fein, M 1983, 'Work measurement and wage incentives', Industrial Engineering, vol. 5, no. 9, pp. 49-61.

FMM 2003, Federation of Malaysian Manufacturer. Retrieved July 14, 2005, from http://www.fmm.org.my/p ne it.asp?NewsID=538\&ThemeID=294\&From=Theme.

Ger, G \& Belk, RW 1996, 'Cross-cultural differences in materialism', Journal of Economic Psychology, vol. 17, no. 1, pp. 55-77.

Gilley, JW \& Maycunich, A 2000, Beyond the learning organization: creating a culture of continuous growth and development through state-of-the-art human resource practices, Perseus Books, New York.

Grensing, L 1996, 'When the carrot can’t be cash', Security Management, vol. 40, no. 12, pp. 25-27.

Halstead, JM 2007, 'Islamic values: a distinctive framework for moral education?', Journal 
of Moral Education, vol. 36, no. 3, pp. 283-296.

Hamidullah, M 1973, Introduction to Islam, 3rd edn, SH Muhammad Ashraf, Lahore, Pakistan.

Hassan, MH 2004, 'Islam Hadhari: Abdullah's vision for Malaysia?', in Institute of Defence and Strategic Studies, Nanyang Technology University, pp. 1-2, October 26, 2004.

Hashim, J 2007, Human Resource Management: Islamic approach, Pearson, Prentice Hall.

Heim, SM 2004, 'Malaysian model - A different kind of Islamic state', The Christian Century, vol. 121, no. 20, pp. 30-33.

Herzberg, F, Mausner, B \& Snyderman, B 1959, The motivation to work, Wiley, New York.

Hofstede, G 1980a, Culture's consequences: international differences in work-related values, Sage Publications, Beverly Hills, CA.

Hofstede, G 1980b, 'Motivation, leaders and organization: do American theories apply abroad?', Organizational Dynamics, pp. 42-63.

Hofstede, G 1991, Culture and organizations (intercultural communication and its importance for survival). Software of the mind, McGraw-Hill, Cambridge, England.

Hofstede, G 2001, Cultural consequences: comparing values, behaviors, institutions, and organizations across nations, 2nd edn, Sage Publication, California.

Huang, KC, Lu, N, Tang, CH \& Huang, CI 2004, 'Fairness perceptions and work attitudes revisited: roles of employee speciality, hospital level and ownership', The International Journal of Human Resource Management, vol. 15, no. 7, pp. 1317-1329.

Islam, R \& Ismail, AZH 2008, 'Employee motivation: a Malaysian perspective', International Journal of Commerce \& Management, vol. 18, no. 4, pp. 344-362.

Kanungo, RN \& Mendonca, M 1988, 'Evaluating Employee Compensation', California Management Review, vol. 31, no. 1, pp. 23-39.

Khan, B, Farooq, A \& Hussain, Z 2010, 'Human resource management: an Islamic perspective', Asia-Pacific Journal of Business Administration, vol. 2, no. 1, p. 17.

Khan, MA 1991, 'The future of Islamic economics', Futures, vol. 23, no. 3, pp. 248-261.

Knoop, R 1994, 'Work values and job satisfaction', The Journal of Psychology, vol. 128, no. 6, pp. 683-690.

Koys, DJ 2001, 'Integrating religious principles and human resource management activities', Teaching Business Ethics, vol. 5, no. 2, pp. 121-139.

Kugel, J \& Schostek, C 2004, 'Rewards for knowledge sharing?', The Gurteen Knowledge. $\begin{array}{lllll}\text { Retrieved on } & \text { April, } & 9 & 2006 & \text { from }\end{array}$ http://www.gurteen.com/gurteen/gurteen.nsf/id/rewards-k-sharing

Levine, HZ 1998, 'How pay should reflect culture', Compensation and Benefits Review, vol. 30, no. 2, pp. 76-77.

Loqman, M 1991, 'A brief note on the Islamic financial system', Managerial Finance, vol. 25, no. 5, pp. 52-59.

Lublin, JS 2006, 'Boards tie CEO pay more tightly to performance; options grants may depend on meeting financial goals; moving beyond a 'Pulse", Wall Street Journal. (Eastern edition), p. A1.

Markovich, PN 1997, 'Mobilizing your human potential', Journal for Quality and 
Participation, vol. 20, no. 2, pp. 48-53.

Martinez, PA 2005, 'Is it always civil society versus Islam', Islam in Southeast Asia: Political, Social and Strategic Challenges for the 21st Century, ISEAS, Singapore, pp. 137-139.

McShulskis, E 1997, 'Well-paid employees are loyal employees', HRMagazine, vol. 42, no. 11, p. 22.

Mendonca, M \& Kanungo, RN 1994, Motivation through effective reward management in developing countries, In: Kanungo, R.N., Mendonca, S. (Eds.) Work Motivation: Models for Developing Countries edn, Sage Publication.

Michaelson, C 2008, 'Moral Luck and Business Ethics ', Journal of Business Ethics, vol. 83, no. 4, pp. 773-787.

Milkovich, GT, Newman, JM \& Gerhart, B 2010, Compensation, 10th edn, Mc Graw Hill, United States.

Morse, JM 2005, 'Evolving trends in qualitative research: advances in mixed-method design', Qualitative Health Research, vol. 15, no. 5, pp. 583-585.

Noor, FA 2004, 'Race, Racism and Islam Hadhari', Malaysiakini. Retrieved on August, 24 2006 from www.malaysiakini.com/columns/30474

Oliver, N 1990, 'Work rewards, work values, and organizational commitment in an employee-owned firm: Evidence from the U.K', Human Relations, vol. 43, no. 6, p. 513.

Osborne, D 2001, 'Paying for results', Government Executive, vol. 33, no. 2, p. 61.

Pandian, S 2008, 'Islam Hadhari - from the non-Muslim perspective', Journal of Humanity, vol. 12, pp. 14-22.

Ramadan, T 2005, 'Rethinking the use of Muslim law', Boston Globe, p. A 15.

Reif, WE, Newstrom, JW \& St. Louis Jr, RD 1976, 'Sex discriminating variable in organizational reward decisions', Academy of Management Journal, vol. 19, no. 3, pp. 469-476.

Sachau, DA 2007, 'Resurrecting the motivation-hygiene theory: Herzberg and the positive psychology movement', Human Resource Development Review, vol. 6, no. 4, pp. 377-393.

Said, S 2008, Islam not the root of Muslim-West Discord, January 15, 2008 from http://findarticles.com/p/articles/mi_8082/is_20080115/ai_n51572669/ (accessed on 18 September 2009)

Seay, RF 2008, 'Contemporary issues in compensation', Community Banker, vol. 17, no. 1, pp. 36-37.

Sharif, M 2003, 'Application of Islamic Economic System in a Contemporary Economy: an Illustration with Poverty and Inequity in the USA', Humanomics, vol. 19, no. 3/4, pp. $41-54$.

Stone, RJ 2005, Human Resource Management, 5th edn, John Wiley \& Sons Australia Ltd., Australia.

Sauer, RL 1999, 'A new approach to salary structures', Compensation and Benefits Review, vol. 21, no. 5, pp. 57-63.

Takeuchi, H 1981, 'Productivity, Learning from the Japanese', California Management 
Review, vol. 23, no. 4, pp. 5-19.

Tayeb, M 1997, 'Islamic revival in Asia and human resource management', Employee Relations, vol. 19 , no. 4 , p. 352.

Vance, CM, McClaine, SR, Boje, DM \& Stage, D 1992, 'An examination of the transferability of traditional performance appraisal principles across cultural boundaries', Management International Review, vol. 32, pp. 313-326.

Zin, AM 2005, 'Islam Hadhari: An Explanation', in Message, ed. Malaysia State Library. Department of Islamic Development Malaysia Putrajaya, Putrajaya, p. 6. 